Canadian Journal of Medicine

WWW.CIKD.CA

\title{
Investigation of Health Status with Psychological Aspects
}

\begin{abstract}
Babak Otoukesh
Clinical fellowship, Universitätsklinikum Bonn, Bonn, Germany

\begin{tabular}{l}
\hline \\
Keywords: \\
General Health, \\
Mental Disorders, \\
Medical Staff, \\
Demographic \\
\hline Received \\
10 May 2019 \\
Received in revised form \\
03 August 2019 \\
Accepted \\
05 November 2019 \\
\hline
\end{tabular}

Correspondence:

Babak.Otoukesh@ukbonn.de

Mental disorders are among the most annoying for some employees in large organizations. Many believe that in order to provide good service in large organizations, it needs to meet minimum standards and pay attention to the types of stress and other mental disorders that result from those centers. Undoubtedly, health care organizations are no exception, but because of the complexity of the structure and the extent of inter-sectoral relationships, the need for this is becoming increasingly important. The purpose of this study was to investigate the general health status of employees with an approach to the psychological aspects. Human resources as an unmatched asset in health care centers have formed one of the most important management concerns in it. Therefore, it is important to examine the mental health status of the staff in the health care centers in view of the increasing pressures and variety of missions of those centers. Finally, this study has been presented effective strategies to improve the mental health of employees and subsequently to improve the quality of health. This is a cross-sectional descriptive study in which all staff working in a health service center was surveyed. The mental health status of the staff of the center was measured by the GHQ-28 questionnaire. Demographic variables, including age, sex, education, field of study, place of employment, were also examined. The study data showed that $93.8 \%$ of the total population were in desirable condition. Considering that more than $6 \%$ of employees lack the desired state of mental health, and physicians and official forces are more prone to disorder than other employees, so paying more attention to appropriate requirements, including necessary measures, meeting facilities and paying attention to the welfare and cultural needs of the staff, should be used to maintain the mental health of staff.
\end{abstract}

CCIKD Publishing

\section{Introduction}

The need to pay attention to the physical and mental health of the staff in health care centers seems to be a necessity. Attention to this is one of the factors providing the quality of service 
delivery in centers. Since the survival of these types of centers depends on fulfilling their mission and achieving their health goals. In a health-care center, the physical and mental health of the staff should be given as much attention and interest in the management of the center as it is to provide services and productivity (Rafati, Tavakoli, Amerion, Hoseinpourfard, \& Nasiri, 2010).

Many believe that in order to provide better services in large organizations, they need to meet minimum standards and pay attention to the types of stress and other mental disorders that result from them.

Undoubtedly, health care organizations are no exception, but because of the complexity of the structure and the extent of inter-sectoral relationships, the need for this is becoming increasingly important.

Human resources as an unmatched asset in health care centers has formed one of the most important management concerns in it, and therefore examining the mental health status of health care workers, given the increasing pressures and variety of its missions. Centers seem to be very important.

Finally, this study has been presented effective strategies to improve the mental health of employees and subsequently to improve the quality of health in selected organizations.

Centers for health and health services, in addition to providing services to their staffs and their families, is considered one of the most important communication institutions with the people and the community. Therefore, these centers have a key role in health domain. In this way, the health care delivery centers can provide a clear example for religious patterns in the beliefs of the people and society by providing appropriate patterns. Since the personnel are faithful, committed and experienced people, neglecting their mental and physical health has a negative impact on the provision of quality and standard services and will leave an inadequate reputation. Therefore, the staff of these centers is valuable and unmatched assets that should be considered in every respect from a health point of view. The staff of these centers, like all health centers, is exposed to a variety of work-related illnesses and in addition to the problems and stresses of the organization are not as well as a military one. Therefore, it is very important to pay attention to the health of these employees and to study them in their various dimensions.

Studies and surveys of different jobs in Iran also show that employees are exposed to a variety of work-related diseases, including chemical, ergonomic, biological, and mental, depending on what they do (Halvani, Dehnavieh, Nodoushan, Fallah, \& Nodoushan, 2013).

The purpose of this study was to investigate the general health status of staff with an approach to mental aspects in selected organizations - Health Services Providers.

\section{Materials and Methods}

In this cross-sectional study, all staff in one of the affiliated medical centers was studied. Six variables and demographic characteristics, including age, sex, marital status, occupation, work experience, and type of staff members with mental disorder, were assessed.

In this study, initially by conducting numerous meetings with relevant health center officials, the goals of the plan were explained to them and they were asked to justify their staff to cooperate with the plan. The staff was then explained how to complete the questionnaire. The data gathering tool was a GHQ-28 questionnaire (Goodwin et al., 2013; Waschgler, RuizHernández, Llor- Esteban, \& García- Izquierdo, 2013), which was prepared and distributed 
among the staff of each department to be distributed among individuals after completion. In addition, general information, including sex, age, marital status, type of activity, work experience and type of membership was also obtained. Data were analyzed using correlation tests.

\section{Results}

Of the 405 subjects studied, 25 (6.2\%) of the staff had mental disorders, 21 of which (84\%) were male and $4(16 \%)$ were female. Fisher exact test showed a significant relationship bet ween sex and mental disorder $(\mathrm{P}<0.01)$. Of the 25 affected, 15 were formal, 7 were contractual and 3 were paid, and 24 were married. The highest percentage of patients were those aged 35-44 years (Figures 1 and 2). By examining the relationship between age and mental disorder, it was found that there was a significant relationship between them $(\mathrm{P}<0.01)$. However, no relationship was found between work experience and illness $(\mathrm{P}<0.05)$. Among the staff of the study centers, although physicians had more mental disorders than other staff, there was no significant relationship between mental disorders and type of activity or occupation $(\mathrm{P}<0.05)$.

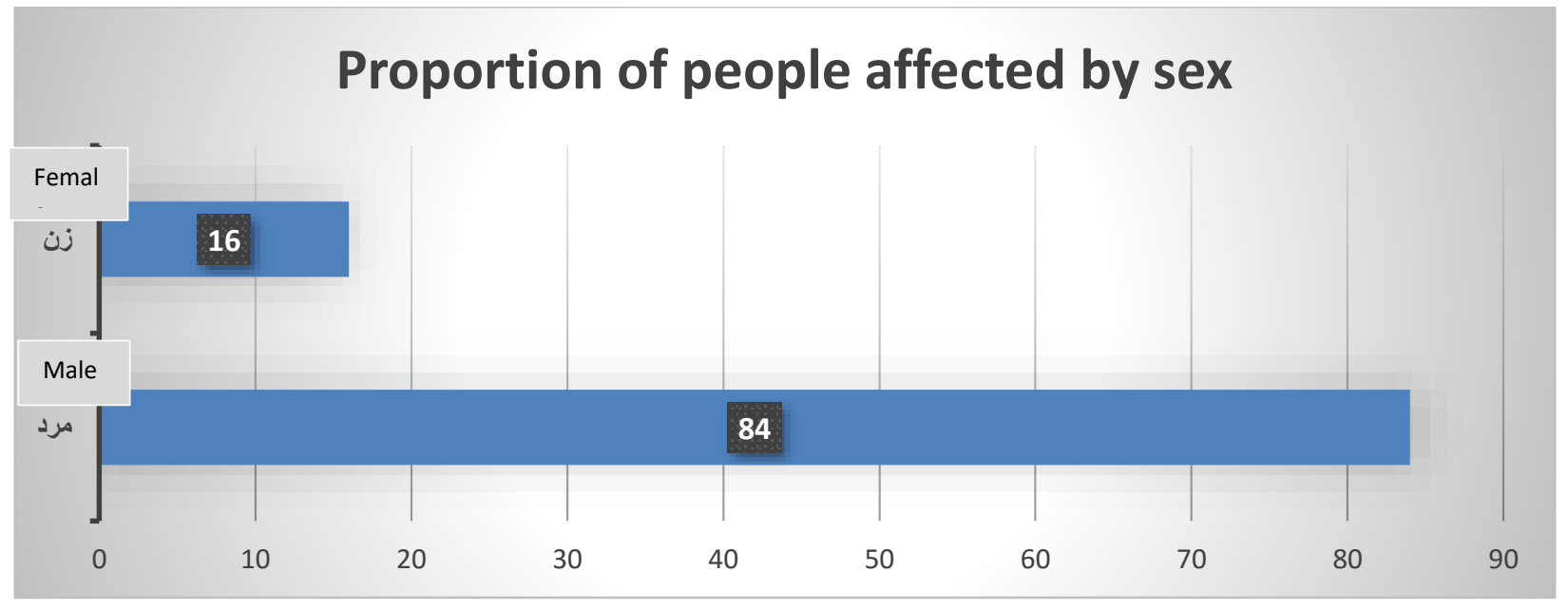

Figure 1. Frequency and proportion of people affected by sex

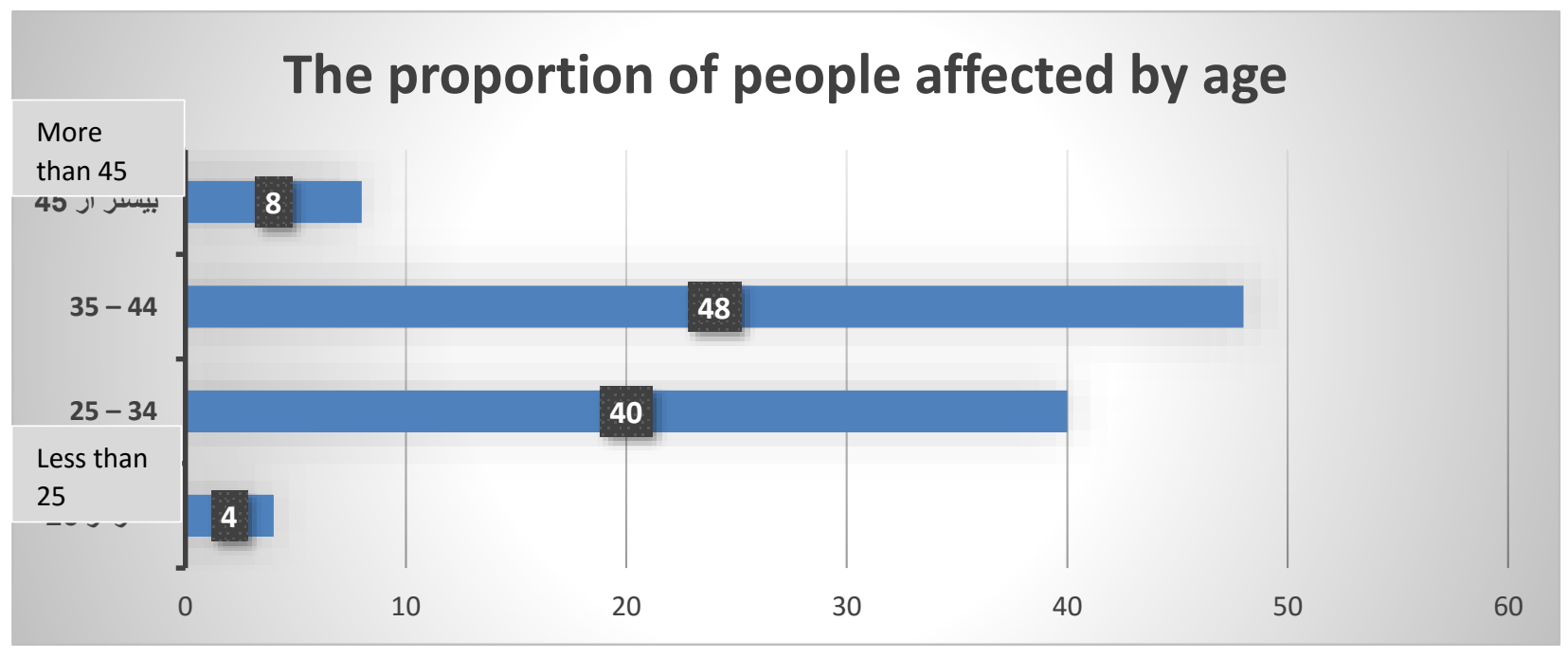

Figure 2. Frequency and proportion of people affected by age 
Out of 405 employees, 25 (6.2\%) had mental disorders. Undoubtedly, every job has its own set of problems and risks, and it is no exception in the medical staff (Rashedi, Foroughan, \& Hosseini, 2012; Sahebi \& Ayatollahi, 2007). Data from other studies indicate that mental health in the general population of Iran is between $11.9 \%$ and $23.8 \%$ (Abdi masooleh, Kaviani, Khaghanizadeh, \& Momeni, 2007). According to the World Health Organization (WHO), 52 million people of all ages suffer from severe mental illness and 250 million suffer from mild illness (12). A Norbala study in the National Health Plan also found that 21 percent of people over 15 years of age in Iran are suspected of having a mental disorder (Sahebi \& Ayatollahi, 2007). The data obtained in this study (6.2\%) are much lower than these figures. In many studies, the relationship between mental health and gender is significant (khaghanizade, Siratinir, Abdi, \& Kaviani, 2007; Sahebi \& Ayatollahi, 2007; Soleimani, Sharifi, \& Tehranidoust, 2006;). This can be due to men's relationship with all types of sensitive missions and heavier responsibilities. In addition, recent studies have shown a high incidence of such cases among married people and the association between marriage and mental disorders (Abdi masooleh et al., 2007; Rahimi, Ahmadi, \& Akhond, 2004). In the present study, more than $80 \%$ of men and $96 \%$ of married people had disorders. It must be expected that such disorders may be higher in older people than young people as their age and their capacity have been reduced. Also, the younger people have less responsibility and work pressure. This issue has also been confirmed in various studies (Abdi masooleh et al., 2007; Rahimi et al., 2004; Soleimani et al., 2006). The results of the present study also showed that the highest percentage of mental disorder (48\%) related to the age group is 35 to 44 years and there is significant correlation between age and mental disorder $(\mathrm{P}<0 / 01)$. Although it is expected that there is a significant relationship between age and work experience as well as the significant relationship between age and mental disorder, out in the present study, there is no meaningful relation. Various studies of course, consider the work experience as one of the effective factors on mental health (Abdi masooleh et al., 2007; khaghanizade et al., 2007; Rahimi et al., 2004) (Tables 1-4)

Table 1

Frequency and Proportion of People Affected by Work Experience

\begin{tabular}{llll}
\hline & & number & percent \\
\hline \multirow{3}{*}{ Experience (years) } & Less than 5 & 5 & 20 \\
& $5-9$ & 12 & 48 \\
& More than 10 & 8 & 32 \\
\hline
\end{tabular}

Table 2

Frequency and Proportion of Affected Individuals by Activity Type

\begin{tabular}{llll}
\hline & & number & percent \\
\hline \multirow{3}{*}{ activity type } & Medicine & 9 & 36 \\
& Nurse & 2 & 8 \\
& Paramedical & 7 & 28 \\
& Service & 7 & 28 \\
\hline
\end{tabular}

Table 3

Frequency and Proportion of People Affected by Marriage

\begin{tabular}{llll}
\hline & & number & Percentage \\
\hline \multirow{2}{*}{ marital status } & Single & 1 & 4 \\
& Married & 24 & 96 \\
\hline
\end{tabular}


Table 4

Frequency and Proportion of People Affected by Membership

\begin{tabular}{llll}
\hline & & number & Percentage \\
\hline \multirow{3}{*}{ membership type } & Official & 15 & 60 \\
& Contractual & 7 & 28 \\
& Daily worker & 3 & 12 \\
\hline
\end{tabular}

\section{Discussion}

According to the International Institute for Occupational Health and Safety, nurses are more at risk of mental illness than other staff at medical centers. In some studies - depending on the purpose of the studies - this was confirmed (Hoseinpourfard, Rafati, \& Babamahmoudi, 2013; Sahebi \& Ayatollahi, 2007; Sirati \& Khaghanizadeh, 2003) and in others, physicians were more at risk than others (Bahreinian, 2011; Rahimi et al., 2004).

The risks arising from different occupations are listed in some resources up to 900 (Daneshmandi, Barati, \& Ahmadi, 2013). The origin of work-related diseases is multi factor, and these are diseases that may arise partially under adverse working conditions, but do not necessarily have a specific risk factor in each case (Reiman et al., 2014). According to statistics published in 2014, more than 101.8 million work hours have been wasted in the work of some of the related diseases in South Africa (Spavins, 2014). In Iran, this issue is one of the elements of the program in the strategic plan of health. Work-related illnesses, in addition to the obvious damages caused by illness, through the elimination of the workforce, the creation of disabilities, the creation of new health care costs, and so on, are also damaging to the country's economic and social development. The importance and prevalence of the issue of communicable diseases, including related diseases, have led researchers at the national and international level to study various issues related to employee's health at different levels (Reiman et al., 2014; Rogers, 2010).

\section{Suggestion}

Job stress affects people's health, reduces the quality of life, and increases the likelihood of injuries occurring (Rahimi et al., 2004). Therefore, it is important to pay close attention at the time of hiring and during work, mental health examinations and controls. In addition, employing staff based on their ability in different positions in the organization, training and empowering staff along with resolving their livelihood problems are some of the strategies to reduce mental disorders in health care staff as well as following practices:

- Increased emotional commitment to employees with satisfaction of rights and benefits and provide adequate employment conditions and provide job security for employees by officials and managers of health and health centers.

- Increasing the level of awareness of the authorities and managers of health centers about work-related diseases and ways to control and reduce them in these centers

- Developing and implementing health and safety guidelines for the various departments of health centers

- Use of psychological counseling services for health care personnel

It is hoped that the set of measures taken will be a step towards preserving and promoting the mental health. 


\section{References}

Abdi masooleh, F., Kaviani, H., Khaghanizadeh, M., \& Momeni, A. A. (2007). The relationship between burnout and mental health among nurses. Tehran University Medical Journal, 65(6), 65-75.

Bahreinian, S. A (2011). Study about stress in groups of assistants in field of medicine. Teb-o-Tazkiyeh, 20(58), 44-49.

Daneshmandi, H., Barati, A., \& Ahmadi, R. (2013). The effect of 6 weeks core stabilization training program on the balance of mentally retarded. Quarterly Journal of Rehabilitation, 14(3), 16-24.

Goodwin, L., Ben-Zion, I., Fear, N. T., Hotopf, M., Stansfeld, S. A., \& Wessely, S. (2013). Are reports of psychological stress higher in occupational studies? A systematic review across occupational and population-based studies. PloS one, 8(11), e78693.

Halvani, G. H., Dehnavieh, R., Nodoushan, I. S., Fallah, H., \& Nodoushan, R. J. (2013). Evaluation of physical health and its relation with history of work accidents in workers of the Central Iron Ore Company of Iran. International Journal of Environmental Health Engineering, 2(1), 39.

Hoseinpourfard, M., Rafati, H., \& Babamahmoudi, S. A. (2013). Job Stress and the Efficacy of Selected Military Managers. Journal of Military Medicine, 15(1), 51-58.

Khaghanizade, M., Siratinir, M., Abdi, F., \& Kaviani, H. (2007). Assessing of mental health level of employed nurses in educational hospitals affiliated to Tehran medical sciences university. Fundamentals of Mental Health, 8(31-32), 141-148.

Rafati, H. A. S. A. N., Tavakoli, H. R., Amerion, A., Hoseinpourfard, M., \& Nasiri, T. (2010). Comparison of HACCP implementation requirements in nutrition department of two military and non-military health-treatment centers. Journal Military Medicine, 11(4), 191-196.

Rahimi, A., Ahmadi, F., \& Akhond, M. R. (2004). An investigation of amount and factors affecting nurses' job stress in some hospitals in Tehran. Journal of Hayat, 10(3), 13-22.

Rashedi, V., Foroughan, M., \& Hosseini, M. A. (2012). Burnout and related demographic variables among Tehran Welfare Organization staffs. Journal of Kermanshah University of Medical Sciences, 16(1), 28-36.

Reiman, A., Putkonen, A., Nevala, N., Nyberg, M., Väyrynen, S., \& Forsman, M. (2015). Delivery truck drivers' work outside their cabs: ergonomic video analyses supplemented with national accident statistics. Human Factors and Ergonomics in Manufacturing and Service Industries, 25(3), 340-352.

Rogers, K. (Ed.) (2010). Medicine and healers through history. Britannica Educational Publishing.

Sahebi L., \& Ayatollahi, M. (2007). Mental health status of hospitals staffs in Shiraz. Quarterly of Horizon of Medical Sciences, 12(4), 26-33.

Sirati, M., \& Khaghanizadeh, M. (2003). The study of relationship stress and efficiency among nursing managers in selected hospital. Journal of Military Medicine, 5(1), 7-33.

Soleimani, K., Sharifi, V., \& Tehranidoust, M. (2006). Occupational burnout in psychiatric staff at Roozbeh Hospital. Advances in Cognitive Science, 7(4), 36-42.

Spavins, M. H. (2014). Factors affecting work status of employees with chronic back pain in South Africa (Published master's thesis). University of the Witwatersrand, Johannesburg. Retrieved from http://hdl.handle.net10539/13749

Waschgler, K., Ruiz- Hernández, J. A., Llor- Esteban, B., \& García- Izquierdo, M. (2013). Patients' aggressive behaviours towards nurses: development and psychometric properties of the hospital aggressive behaviour scale- users. Journal of Advanced Nursing, 69(6), 1418-1427. 